\title{
Synergistic flame retardant effects between sepiolite and magnesium hydroxide in ethylene-vinyl acetate (EVA) matrix
}

\author{
N. H. Huang ${ }^{1,2 *}$ Z. J. Chen ${ }^{1,2}$, C. H. Yi ${ }^{1,2}$, J. Q. Wang 3 \\ ${ }^{1}$ Key Laboratory of Green Processing and Functional Textiles of New Textile Materials, Ministry of Education, Wuhan \\ University of Science and Engineering, Wuhan, 430073, P.R. China \\ ${ }^{2}$ Department of Polymer Science and Engineering, Wuhan University of Science and Engineering, Wuhan, 430073, P.R. \\ China \\ ${ }^{3}$ National Laboratory of Flame Retardant Materials, Beijing Institute of Technology, Beijing, 100081, P.R. China
}

Received 11 December 2009; accepted in revised form 9 February 2010

\begin{abstract}
Some customers are reluctant to change, because the halogen-free solutions may have higher cost. This is one of the reasons that the synergistic effect is always the subject for researchers to pursue. The synergy between sepiolite and magnesium hydroxide (MH) in halogen-free flame retardant ethylene-vinyl acetate (EVA) copolymer was investigated in the paper through some common facilities, such as limiting oxygen index (LOI), UL-94 test, thermogravimetric analysis (TGA), differential thermal analysis (DTA) and cone calorimeter test (CCT). In the wake of the positive results from the LOI and UL-94 tests, the CCT data indicated not only the reduction of heat release rate (HRR) and mass loss rates (MLR), but also prolonged ignition time (TTI) and depressed smoke release (SR) were observed during combustion. Simultaneously, the tensile strength and Young's modulus of the system were also much better improved with the increase of sepiolite added due to the hydrogen bonds between silanol groups attached to the sepiolite molecules and the ester groups of EVA. The synergistic mechanism has been discussed in the paper in terms of the barrier mechanism in the condensed phase.
\end{abstract}

Keywords: polymer composites, synergistic effect, flame retardant EVA copolymer, sepiolite, magnesium hydroxide

\section{Introduction}

Ethylene-vinyl acetate (EVA) copolymers with different acetate contents are widely used in many fields, particularly in the wire and cable industry as excellent jacketing materials with the required physical and mechanical properties [1,2]. Due to their facile flammability and awful smoke emission while burning, their practical application has been strictly limited. To achieve the required flame retardant grade of low smoke and non-toxic character, metal hydroxides, e.g. magnesium hydroxide $(\mathrm{MH})$ or aluminum hydroxide, should be added in a great amount, say, up to 50-60\% mass fraction, in gen- eral. However, high filler loading leads always without exception to a deterioration of the mechanical performance in the composites. One of the appropriate ways is to bring all the synergistic factors into play, i.e. the full use of synergistic agents (or additives) in the system in order to reduce the amount of flame retardant as much as possible.

In recent years, many researches have published similar results related e.g. to zinc borate [3-5], multiwalled carbon nanotubes [6], Fe-MMT[7], layered double hydroxide [8], rubber [9], organo-modified montmorillonite [10], silicon [11], fumed silica [1], talc [12], expandable graphite [13], zinc 
hydroxystannate [14] and ammonium polyphosphate [15], combined with MH. Nevertheless, very few publications appear in the literature concerning the sepiolite used in combination with $\mathrm{MH}$ in EVA matrix.

Sepiolite is a family of fibrous hydrated magnesium silicate with the theoretical half unit-cell formula $\mathrm{Si}_{12} \mathrm{O}_{30} \mathrm{Mg}_{8}(\mathrm{OH})_{4}\left(\mathrm{OH}_{2}\right)_{4} \cdot 8 \mathrm{H}_{2} \mathrm{O}$ [16], similar to the 2:1 layered structure of montmorillonite, consisting of two tetrahedral silica sheets enclosing a central sheet of octahedral magnesia except that the layers lack continuous octahedral sheets [1621]. The discontinuity of the silica sheets gives rise to the presence of silanol groups $(\mathrm{Si}-\mathrm{OH})$ at the edges of the tunnels, which are the channels opened to the external surface of the sepiolite particles. The presence of silanol groups $(\mathrm{Si}-\mathrm{OH})$ can enhance the interfacial interaction between sepiolite and polar polymers.

In this paper, the synergistic effects of sepiolite and $\mathrm{MH}$ on the flame retardant and thermal properties of the EVA/MH/sepiolite composites have been accomplished through limiting oxygen index (LOI), UL-94 test, thermal analysis (TG/DTA), cone calorimeter test and the measurement of mechanical properties.

\section{Experimentals}

\subsection{Materials}

The EVA copolymer used was a commercial grade Evatane ${ }^{\circledR} 2803$ (Arkema), with a vinyl acetate content of $28 \%$ mass fraction and a melt flow index of $3.6 \mathrm{~g} / 10 \mathrm{~min}$. Magnesium hydroxide( $\mathrm{MH})$, with an average particle size $2 \mu \mathrm{m}$, was obtained from Liaoning Gaizhou Inorganic Chemical Plant, China. Micronized pristine sepiolite (SP) was kindly supplied by Tolsa SA (Spain). The formulations are listed in Table 1.

Table 1. Formulation of EVA composites

\begin{tabular}{|l|c|c|c|}
\hline Sample code & EVA [\%] & MH [\%] & SP [\%] \\
\hline EVA & 100 & 0 & 0 \\
\hline EVA1 & 45 & 55 & 0 \\
\hline EVA2 & 45 & 54 & 1 \\
\hline EVA3 & 45 & 53 & 2 \\
\hline EVA4 & 45 & 52 & 3 \\
\hline EVA5 & 45 & 51 & 4 \\
\hline EVA6 & 45 & 50 & 5 \\
\hline EVA7 & 45 & 47 & 8 \\
\hline
\end{tabular}

\subsection{Sample preparation}

Prior to mixing and getting the sepiolite dried the sample was heated first at $100^{\circ} \mathrm{C}$ for $4 \mathrm{~h}$ and cooled slowly then to room temperature under vacuum for $16 \mathrm{~h}$. All samples were melt-mixed via a twin-roll mill (XK-160, made in Jiangdu company, China) at $150^{\circ} \mathrm{C}$ for $15 \mathrm{~min}$, and then hot-pressed under $10 \mathrm{MPa}$ for $5 \mathrm{~min}$ at $140^{\circ} \mathrm{C}$ taking the shape of sheets according to the prescriptive requirements.

\subsection{Characterization}

\subsubsection{Limiting oxygen index (LOI)}

The LOI measurements were carried out using a JF3 type instrument (Jiangning Analysis Instrument Factory, China) according to GB 2406-80 (ASTM D 2863-77). The samples used for the test were of dimensions $130 \mathrm{~mm} \times 6.5 \mathrm{~mm} \times 3 \mathrm{~mm}$.

\subsubsection{UL-94 test}

The UL-94 vertical test was measured on a CZF-2 type instrument (Jiangning Analysis Instrument Factory, China) with sample dimensions of $127 \mathrm{~mm} \times 12.7 \mathrm{~mm} \times 3 \mathrm{~mm}$ according to ASTM D 635-77. UL-94 test results are classified by burning ratings $\mathrm{V}-0, \mathrm{~V}-1$ or $\mathrm{V}-2$. V-0 rating represents the best flame retardancy of polymeric materials.

\subsubsection{Thermal analysis}

All runs were carried out on a standard TG-DTA instrument (STA 449C, manufactured by Netzsch, Germany). The samples were examined in $\mathrm{Al}_{2} \mathrm{O}_{3}$ crucibles ( $6 \mathrm{~mm}$ in diameter and $4 \mathrm{~mm}$ in height) in direct contact with the heat-flux plate. Sample weight was approximately $8 \mathrm{mg}$ and the runs carried out in high purity $\mathrm{N}_{2}$, flowing at $20 \mathrm{~cm}^{3} / \mathrm{min}$. The heating rate was $10^{\circ} \mathrm{C} / \mathrm{min}$ over the range $25-700^{\circ} \mathrm{C}$.

\subsubsection{Cone calorimeter test}

Combustion experiments were performed in a cone calorimeter (Fire Testing Technology, UK) at an incident heat flux of $35 \mathrm{~kW} / \mathrm{m}^{2}$ according to ISO 5660. The bottom and edges of each specimen with a dimension of $100 \mathrm{~mm} \times 100 \mathrm{~mm} \times 3 \mathrm{~mm}$ are wrapped with aluminum foil. All samples were run in duplicate and the average value is reported. Var- 
ious parameters can be measured including time to ignition (TTI), heat release rate (HRR) as a function of time, peak of heat release rate (PHRR), mass loss rate, and so on. The experimental error of data from the cone calorimeter was about $5 \%$.

\subsubsection{Mechanical properties testing}

The tensile strength and elongation at break were measured with an Instron Universal Tester Machine (model 5566) at $(25 \pm 2)^{\circ} \mathrm{C}$ with a crosshead speed of $50 \mathrm{~mm} / \mathrm{min}$, according to ASTM D 638. In the above-mentioned several measurements, five samples for each test were usually analyzed in order to obtain reproducible results and determine the average values.

\section{Results and discussion}

\subsection{Thermal analysis}

To exemplify the thermal behaviour the TG and DTG curves of virgin EVA, MH, EVA/MH and EVA/MH/SP 3\% composites are shown in Figures 1 and 2, respectively. On heating the virgin EVA decomposes within the temperature range of $270 \sim 520^{\circ} \mathrm{C}$ in $\mathrm{N}_{2}$ atmosphere: The first stage (270$395^{\circ} \mathrm{C}$ ) is attributed to the evolution of acetic acid due to the decomposition of vinyl acetate groups

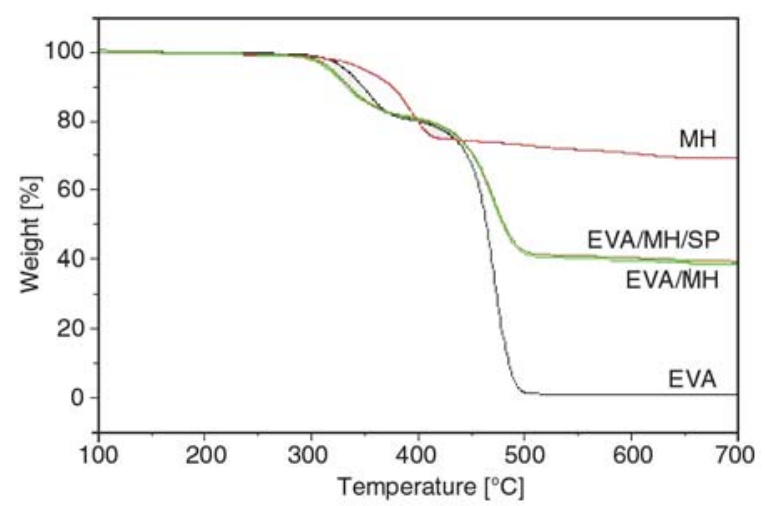

Figure 1. TG curves of virgin EVA, MH, EVA/MH and EVA/MH/SP $3 \%$ composites in $\mathrm{N}_{2}$ at a heating rate of $10^{\circ} \mathrm{C} / \mathrm{min}$

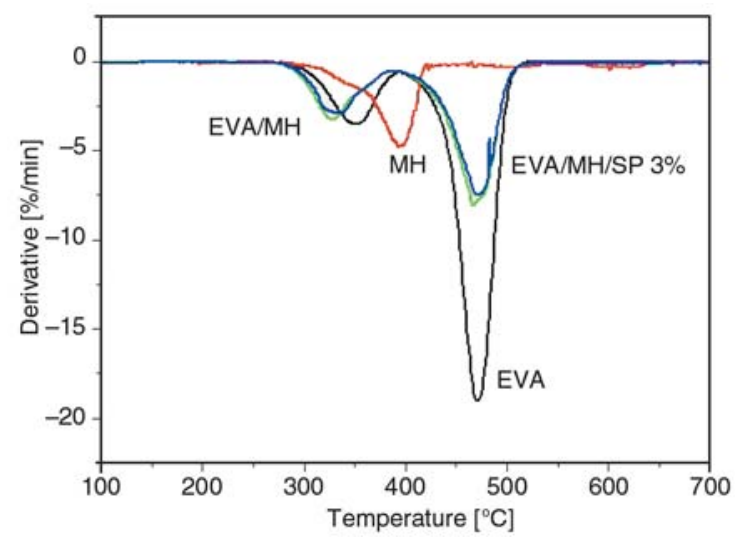

Figure 2. DTG curves of virgin EVA, MH, EVA/MH and EVA/MH/SP $3 \%$ composites in $\mathrm{N}_{2}$ at heating rate of $10^{\circ} \mathrm{C} / \mathrm{min}$

[22]; the second step $\left(395-520^{\circ} \mathrm{C}\right)$ corresponds to the degradation of the polyethylene chains. As reported, the first step of weight loss for EVA/MH composite occurs in the range of $276-388^{\circ} \mathrm{C}$ due to the dehydration reaction of $\mathrm{MH}$ and the loss acetic acid in the EVA at the range of $270-395^{\circ} \mathrm{C}$. The second step of weight loss occurs within the temperature range of $388-520^{\circ} \mathrm{C}$ due to the degradation of the polyethylene chains. In the experiment, the EVA/MH/SP 3\% composite shows the same degradation steps as EVA/MH composite.

The $5 \%$ mass loss temperature $\left(T_{5} \%\right)$, the maximum mass loss temperature ( $T_{\max 1}$ and $T_{\max 2}$ ), the maximum rate of weight loss $\left(R_{\max }\right)$ and residue yield values at $650^{\circ} \mathrm{C}$ are summarized in Table 2 .

As revealed in Table 2 the $T_{5} \%$ for both EVA/MH and EVA/MH/SP 3\% composites are similar to one another and deviated about $15^{\circ} \mathrm{C}$ from the virgin EVA. Regarding the differences in $T_{\max 1}$ and $T_{\max 2}$ for both composites, they are only 8 and $5^{\circ} \mathrm{C}$, respectively. To access the two composites of $\mathrm{EVA} / \mathrm{MH}$ and EVA/MH/SP 3\% the variation of the $R_{\max 1}$ (from 3.3 to $2.9 \% / \mathrm{min}$ ) and $R_{\max 2}$ (from 8.1 to $7.5 \% / \mathrm{min}$ ) and the residue yield at $650^{\circ} \mathrm{C}$ (from 38.0 to $39.8 \%$ ) it is true indeed that the participation of sepiolite does decrease the rate of weight loss.

Table 2. TGA data of virgin EVA, $\mathrm{MH}$ and their composites under $\mathrm{N}_{2}$ at heating rate of $10^{\circ} \mathrm{C} / \mathrm{min}$

\begin{tabular}{|l|c|c|c|c|}
\hline \multicolumn{1}{|c|}{ Sample } & $\mathbf{T}_{\mathbf{5} \%}\left[{ }^{\circ} \mathbf{C}\right]$ & $\mathbf{T}_{\max 1} / \mathbf{T}_{\max }\left[{ }^{\circ} \mathbf{C}\right]$ & $\mathbf{R}_{\max 1} / \mathbf{R}_{\max 2}[\mathbf{\%} / \mathbf{m i n}]$ & Residue yield at $\mathbf{6 5 0}{ }^{\circ} \mathbf{C}[\mathbf{w t} \%$ ] \\
\hline EVA & 331 & $351 / 471$ & $3.5 / 19.0$ & 0.9 \\
\hline MH & 348 & 396 & 4.7 & 38.4 \\
\hline EVA/MH & 316 & $327 / 467$ & $3.3 / 8.1$ & 39.9 \\
\hline EVA/MH/SP 3\% & 317 & $335 / 472$ & $2.9 / 7.5$ & \\
\hline
\end{tabular}

$T_{5 \%}$ is the temperature at 5\% weight loss; $T_{\max }$ is the temperature at which the rate of weight loss reaches a maximum.

$R_{\max }$ is the maximum rate of weight loss. 


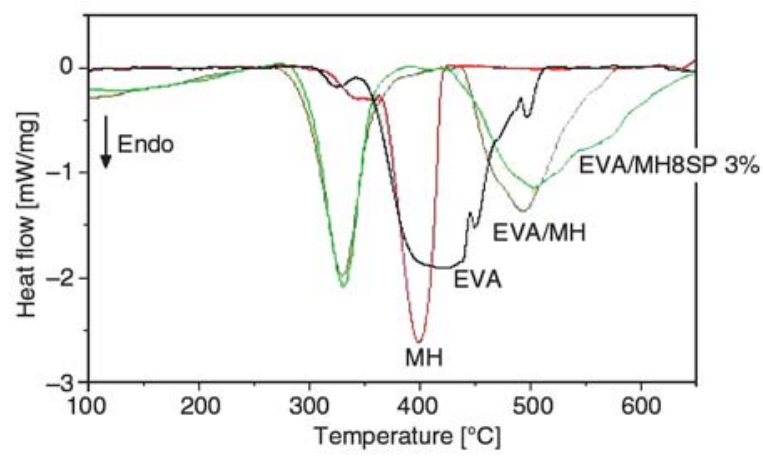

Figure 3. DTA curves of virgin EVA, MH, EVA/MH and EVA/MH/SP $3 \%$ composites in $\mathrm{N}_{2}$ at a heating rate of $10^{\circ} \mathrm{C} / \mathrm{min}$

Four DTA curves are collected in Figure 3. For virgin $\mathrm{MH}$ two peaks can be observed, i.e. a shoulder peak at $339^{\circ} \mathrm{C}$ followed by a strong endothermic peak (maximum at $398^{\circ} \mathrm{C}$ ) due to the dehydration of magnesium hydroxide. EVA curve gives two endothermic peaks within the range of $270-500^{\circ} \mathrm{C}$. As for the composite of EVA/MH two endothermic peaks at $328^{\circ} \mathrm{C}$ corresponding to the dehydration of $\mathrm{MH}$ and the peak at $491^{\circ} \mathrm{C}$ corresponding to the decarboxylation of EVA and thermal decomposition of the polyethylene chains. The DTA curve of the EVA/MH/SP 3\% composite almost overlaps with that of the EVA/MH composite in the range of $270-650^{\circ} \mathrm{C}$. More specifically, it has been noticed that the second endothermic DTA curves for both composites (Figure 3) are somewhat inconsistent with those in TG and DTG results (Figure 2). According to Tartaglione et al. [21], pristine sepiolite undergoes a multi-step dehydration process on heating in the range $50-850^{\circ} \mathrm{C}$. Some changes seem to occur and affect the interaction in the system. Further investigation is still ongoing in the lab.

\subsection{Cone calorimeter study}

Based on the oxygen consumption principle the small-scale cone calorimeter has widely been used to evaluate the characteristics of materials on combustion with the aid of some parameters, like, time to ignition (TTI), peak heat release rate (PHRR) and fire performance index (FPI) (defined as a ratio

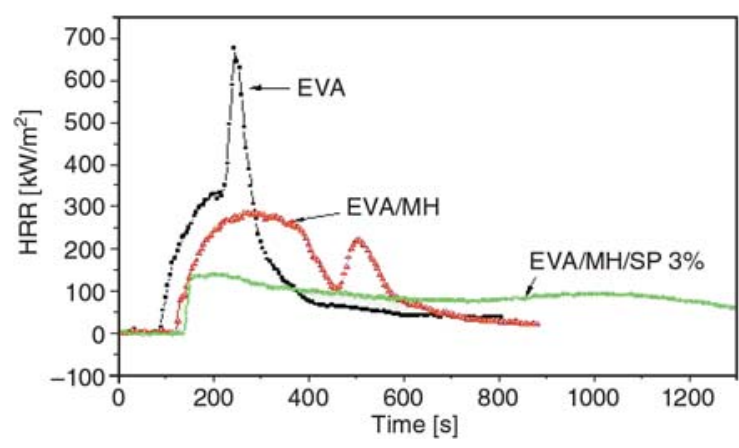

Figure 4. HRR vs time curves for virgin EVA and flame retarded EVA composites $\left(35 \mathrm{~kW} / \mathrm{m}^{2}\right)$

of TTI/PHRR) [23]. Surely, the greater the FPI value, the better the fire resistance.

Figure 4 presents three HRR curves, of which all data were listed in Table 3 . The curve of virgin EVA sample obviously consists of two peaks. The former corresponds to the acetic acid emitted from the thermal decomposition. The latter peak with sharpness (PHRR of $677 \mathrm{~kW} / \mathrm{m}^{2}$ ) corresponds to the decomposition of the residual ethylenic chain appears over the range of 200 400 s.

The sample EVA1 (55\% mass fraction of $\mathrm{MH}$, see Table 1) gives $271 \mathrm{~kW} / \mathrm{m}^{2}$ (PHRR) dramatic declination in HRR with in contrast with virgin EVA. For EVA4 (EVA/MH/SP 3\%) the combustion time is extended to $730 \mathrm{~s}$ from the $715 \mathrm{~s}$ of virgin EVA. EVA4, which is $132 \mathrm{~kW} / \mathrm{m}^{2}$, lower than $271 \mathrm{~kW} / \mathrm{m}^{2}$ of the EVA1 which does not contain sepiolite (Table 3). Among these samples the EVA/MH/ SP 3\% composite shows the lowest EHC, longest TTI and the highest FPI value 1.045, implying the best fire retardance. The above data indicate that sepiolite has good synergistic flame retardant effect with $\mathrm{MH}$ in the EVA/MH/SP composites. From the these results, the synergistic mechanism of sepiolite and $\mathrm{MH}$ in the EVA is probably due to the physical process in the condensed phase leading to the formation of a more stable barrier, which efficiently prevents the heat and mass transfer in fire.

The mass loss rate (MLR) is another parameter of importance in the study of combustion. As depicted in Figure 5 quite similar trends for both HRR and MLR curves are seen. Again the EVA/MH/SP 3\%

Table 3. Cone data of virgin EVA and flame retardant EVA composites

\begin{tabular}{|l|c|c|c|c|c|}
\hline \multicolumn{1}{|c|}{ Sample } & TTI [s] & PHRR [kW/m²] & FPI [m's/kW] & Average EHC [MJ/kg] & Combustion time [s] \\
\hline EVA & 84 & 677 & 0.124 & 28.3 & 715 \\
\hline EVA1 & 127 & 271 & 0.469 & 23.4 & 730 \\
\hline EVA4 & 138 & 132 & 1.045 & 21.8 & 1160 \\
\hline
\end{tabular}




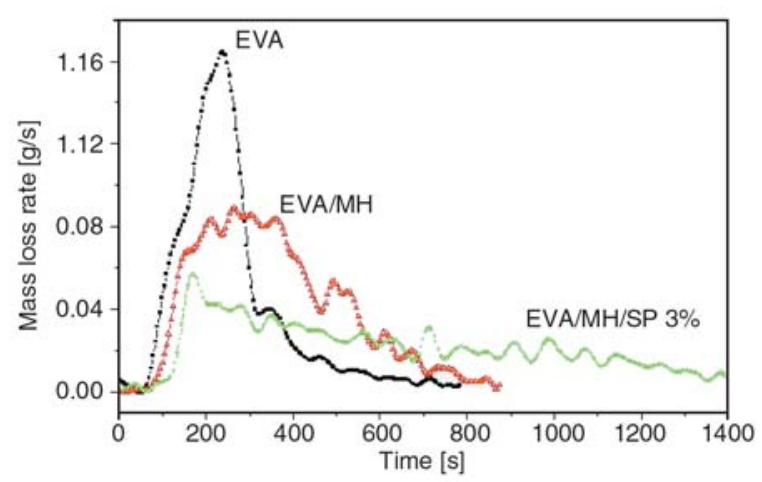

Figure 5. MLS curves for virgin EVA and flame retarded EVA composites $\left(35 \mathrm{~kW} / \mathrm{m}^{2}\right)$

composite gives lower MLR values than the EVA/MH composite does. These results indicate again that the flame retardant synergistic effects of sepiolite with MH apparently decrease the MLR value of the EVA/MH/SP composite.

Figure 6 shows another plot for total heat release (THR) of all samples. Similar conclusion can be drawn that the THR goes down while the flame retardant $\mathrm{MH}$ and $\mathrm{MH} / \mathrm{SP}$ were incorporated in. Consequently, it is also suggested that the synergistic effect between $\mathrm{MH}$ and sepiolite is well deserved in the system.

The emission of smoke is recognized as another important focus in the halogen-free flame retardant system. The mean specific extinction area (SEA), total smoke release (TSR), the mean carbon monoxide yield and carbon dioxide yield derived from cone calorimetry are summarized in Table 4.

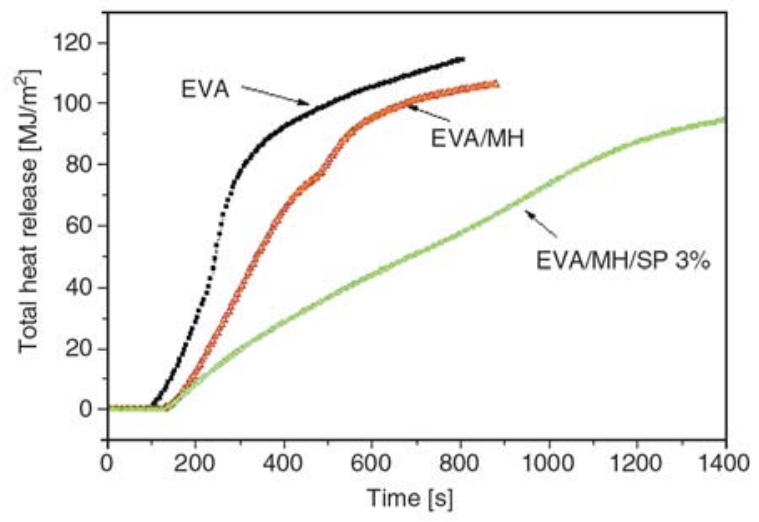

Figure 6. Total heat release (THR) curves for virgin EVA and flame retarded EVA at a heat flux of $35 \mathrm{~kW} / \mathrm{m}^{2}$
It clearly shows that both the smoke emission and carbon oxides yielded during combustion process are depressed by the incorporation of sepiolite.

\subsection{LOI and UL 94 testing}

Table 5 presents the LOI values and UL 94 testing results of the flame retarded EVA composites at the total amount of 55\% mass fraction additives kept constant. As can be seen from Table 5 the LOI value of sample EVA1 containing 55\% MH mass fraction shows a value of $31.2 \%$ contrasting to the value of $17.8 \%$ for the virgin EVA. At $3 \%$ mass fraction of sepiolite the LOI reaches up to the maximum of $33.6 \%$ and passed the grade V-0. The LOI values begin to drop down since then along with further increase of the sepiolite. Apparently, even at $8 \%$ loading the sepiolite seems to be still working, although the LOI value decreases somehow to $32.2 \%$. With 1 and $2 \%$ mass fraction of sepiolite the samples reach to pass the grade V-2 and V-1 respectively. Further increasing to 3 and $4 \%$, they are able to pass the $\mathrm{V}-0$ rating as revealed by samples EVA4 and EVA5. It indicates that an appropriate amount of sepiolite may cause the synergistic effect in the EVA/MH/SP composites more efficient.

Table 5. LOI and UL94 test results

\begin{tabular}{|l|c|c|}
\hline \multicolumn{1}{|c|}{ Sample code } & LOI [\%] & UL 94 \\
\hline EVA & 17.8 & Fail, flame dripping \\
\hline EVA1 & 31.2 & Fail, flame dripping \\
\hline EVA2 & 32.8 & V-2 \\
\hline EVA3 & 33.2 & V-1 \\
\hline EVA4 & 33.6 & V-0 \\
\hline EVA5 & 33.3 & V-0 \\
\hline EVA6 & 33.0 & V-1 \\
\hline EVA7 & 32.2 & V-2 \\
\hline
\end{tabular}

\subsection{Mechanical properties}

At the cutting edge is the mechanical properties of the system, which is of vital importance in applications and may possess itself of some relevance to other properties, say, thermal and/or flame retardant properties. The mechanical properties of vir-

Table 4. Data of smoke obtained from the cone calorimetry

\begin{tabular}{|l|c|c|c|c|c|}
\hline \multicolumn{1}{|c|}{ Sample } & Mean SEA $\left[\mathbf{m}^{\mathbf{2}} / \mathbf{k g}\right]$ & TSR $\left[\mathbf{m}^{2} / \mathbf{m}^{2}\right]$ & Mean CO yield $\left[\mathbf{m}^{2} / \mathbf{m}^{2}\right]$ & mean $\mathbf{C O}_{2}$ yield $\left[\mathbf{m}^{2} / \mathbf{m}^{2}\right]$ & $\mathbf{C O}_{\mathbf{C O O}} \mathbf{r a t i o}$ \\
\hline EVA & 285 & 1015 & 0.048 & 2.35 & 0.0204 \\
\hline EVA1 & 269 & 913 & 0.039 & 2.07 & 0.0188 \\
\hline EVA4 & 227 & 689 & 0.027 & 1.93 & 0.0140 \\
\hline
\end{tabular}


Table 6. Mechanical properties of virgin EVA and flame retardant EVAcomposites

\begin{tabular}{|l|c|c|c|c|c|c|}
\hline Sample code & EVA [\%] & MH [\%] & SP [\%] & Tensile strength [MPa] & Elongation at break [\%] & Young's modulus [MPa] \\
\hline EVA & 100 & 0 & 0 & 26.0 & 960 & 13.6 \\
\hline EVA1 & 45 & 55 & 0 & 8.6 & 148 & 50.2 \\
\hline EVA2 & 45 & 54 & 1 & 8.7 & 114 & 58.2 \\
\hline EVA3 & 45 & 53 & 2 & 8.9 & 201 & 85.9 \\
\hline EVA4 & 45 & 52 & 3 & 9.4 & 118 & 86.8 \\
\hline EVA5 & 45 & 51 & 4 & 10.7 & 168 & 94.3 \\
\hline EVA6 & 45 & 50 & 5 & 11.4 & 146 & 115.1 \\
\hline EVA7 & 45 & 47 & 8 & 11.9 & & \\
\hline
\end{tabular}

gin EVA and formulations with and without sepiolite are given in Table 6.

Taking EVA1 as an example, the addition of MH by great amount into EVA matrix strongly reduces the tensile strength and elongation at break, but oppositely for the Young's modulus. A remarkable change is observed for the Young's modulus, while a small amount of sepiolite is incorporated. The fact that sepiolite has little effect on the elongation at break of the EVA/MH/SP composites, but distinct effect on the Young's modulus probably ascribed to the complex interactions between the polar EVA and the silanol groups of the high aspect-ratio of the sepiolite [24]. Hydrogen bonding may also be expected to take part in between the ester groups of EVA and the characteristic silanol groups.

\section{Conclusions}

The profitable participation of sepiolite in the EVA/Mg(OH $)_{2}$ turns out to be a fair opportunity of appearing in public to show the importance of synergistic effect, supported by a many tested techniques, such as, TGA, DTA, CONE calorimetry, LOI, UL 94, etc. An appropriate amount, say 3\% mass fraction, of sepiolite enables some properties to be improved, if compared with the case without sepiolite. The synergistic flame retardant mechanism can be explained primarily in terms of the barrier mechanism in the condensed phase, which prevents the happening of heat and mass transfer through the barrier in the fire. In this respect the strengthened mechanical properties through the interactions between the ester groups of EVA and the characteristic silanol groups of the sepiolite, is likely the premise for the improved flame retardance of the composites.

\section{References}

[1] Fu M., Qu B.: Synergistic flame retardant mechanism of fumed silica in ethylene-vinyl acetate/magnesium hydroxide blends. Polymer Degradation and Stability, 85, 633-639 (2004).

DOI: $10.1016 /$ j.polymdegradstab.2004.03.002

[2] Riva A., Camino G., Fomperie L., Amigouët P.: Fire retardant mechanism in intumescent ethylene vinyl acetate compositions. Polymer Degradation and Stability, 82, 341-346 (2003).

DOI: $\underline{10.1016 / \mathrm{S} 0141-3910(03) 00191-5}$

[3] Carpentier F., Bourbigot S., Bras M. L., Delobel R., Foulon M.: Charring of fire retarded ethylene vinyl acetate copolymer - Magnesium hydroxide/zinc borate formulations. Polymer Degradation and Stability, 69, 83-92 (2000).

DOI: $\underline{10.1016 / \mathrm{S} 0141-3910(00) 00044-6}$

[4] Carpentier F., Bourbigot S., Bras M. L., Delobel R.: Rheological investigations in fire retardancy: Application to ethylene-vinyl-acetate copolymer-magnesium hydroxide/zinc borate formulations. Polymer International, 49, 1216-1221 (2000).

DOI: 10.1002/1097-0126(200010)49:10<1216::AIDPI515>3.0.CO;2-S

[5] Durin-France A., Ferry L., Cuesta J. L., Crespy A.: Magnesium hydroxide/zinc borate/talc compositions as flame-retardants in EVA copolymer. Polymer International, 49, 1101-1105 (2000).

DOI: 10.1002/1097-0126(200010)49:10<1101::AIDPI523>3.0.CO;2-5

[6] Ye L., Wu Q., Qu B.: Synergistic effects and mechanism of multiwalled carbon nanotubes with magnesium hydroxide in halogen-free flame retardant EVA/ MH/MWNT nanocomposites. Polymer Degradation and Stability, 94, 751-756 (2009). DOI: 10.1016/j.polymdegradstab.2009.02.010

[7] Zhang Y., Hu Y., Song L., Wu J., Fang S.: Influence of Fe-MMT on the fire retarding behavior and mechanical property of (ethylene-vinyl acetate copolymer/ magnesium hydroxide) composite. Polymers for Advanced Technologies, 19, 960-966 (2008). DOI: $10.1002 /$ pat.1059 
[8] Zhang G., Ding P., Zhang M., Qu B.: Synergistic effects of layered double hydroxide with hyperfine magnesium hydroxide in halogen-free flame retardant EVA/HFMH/LDH nanocomposites. Polymer Degradation and Stability, 92, 1715-1720 (2007). DOI: 10.1016/j.polymdegradstab.2007.06.004

[9] Gui H., Zhang X., Dong W., Wang Q., Gao J., Song Z., Lai J., Liu Y., Huang F., Qiao J.: Flame retardant synergism of rubber and $\mathrm{Mg}(\mathrm{OH})_{2}$ in EVA composites. Polymer, 48, 2537-2541 (2007).

DOI: $\underline{10.1016 / j . p o l y m e r .2007 .03 .019}$

[10] Laoutid F., Gaudon P., Taulemesse J. M., Cuesta J. M., Velasco J. I., Piechaczyk A.: Study of hydromagnesite and magnesium hydroxide based fire retardant systems for ethylene-vinyl acetate containing organomodified montmorillonite. Polymer Degradation and Stability, 91, 3074-3082 (2006).

DOI: 10.1016/j.polymdegradstab.2006.08.011

[11] Huang H., Tian M., Liu L., He Z., Chen Z., Zhang L.: Effects of silicon additive as synergists of $\mathrm{Mg}(\mathrm{OH})_{2}$ on the flammability of ethylene vinyl acetate copolymer. Journal of Applied Polymer Science, 99, 32033209 (2006).

DOI: $10.1002 / a p p .22494$

[12] Clerc L., Ferry L., Leroy E., Cuesta J. M.: Influence of talc physical properties on the fire retarding behaviour of (ethylene-vinyl acetate copolymer/magnesium hydroxide/talc) composites. Polymer Degradation and Stability, 88, 504-511 (2005).

DOI: $10.1016 /$ j.polymdegradstab.2004.12.010

[13] Li Z., Qu B.: Flammability characterization and synergistic effects of expandable graphite with magnesium hydroxide in halogen-free flame-retardant EVA blends. Polymer Degradation and Stability, 81, 401-408 (2003). DOI: 10.1016/S0141-3910(03)00123-X

[14] Cross M. S., Cusack P. A., Hornsby P. R.: Effects of tin additives on the flammability and smoke emission characteristics of halogen-free ethylene-vinyl acetate copolymer. Polymer Degradation and Stability, 79, 309-318 (2003). DOI: $10.1016 / \mathrm{S} 0141-3910(02) 00294-X$

[15] Bourbigot S., Duquesne S., Sebih Z., Segura S., Delobel R.: Synergistic aspects of the combination of magnesium hydroxide and ammonium polyphosphate in flame retardancy of ethylene vinyl acetate copolymer. Fire and polymers IV: Materials and concepts for hazard prevention. in 'ACS symposium series' (eds.: Wilkie C. A., Nelson G. L.) Oxford University Press, Washington, vol 922, 200-212 (2006).
[16] Zheng Y., Zheng Y.: Study on sepiolite-reinforced polymeric nanocomposites. Journal of Applied Polymer Science, 99, 2163-2166 (2006).

DOI: $10.1002 /$ app. 22337

[17] Tartaglione G., Tabuani D., Camino G., Moisio M.: PP and PBT composites filled with sepiolite: Morphology and thermal behaviour. Composites Science and Technology, 68, 451-460 (2008).

DOI: $10.1016 /$ j.compscitech.2007.06.023

[18] Alkan M., Benlikaya R.: Poly(vinyl alcohol) nanocomposites with sepiolite and heat-treated sepiolites. Journal of Applied Polymer Science, 112, 3764 3774 (2009).

DOI: $10.1002 / \mathrm{app} .29830$

[19] Chen H., Zheng M., Sun H., Jia Q.: Characterization and properties of sepiolite/polyurethane nanocomposites. Materials Science and Engineering A, 445-446, 725-730 (2007).

DOI: $10.1016 /$ j.msea.2006.10.008

[20] Ma J., Bilotti E., Peijs T., Darr J. A.: Preparation of polypropylene/sepiolite nanocomposites using supercritical $\mathrm{CO}_{2}$ assisted mixing. European Polymer Journal, 43, 4931-4939 (2007).

DOI: $\underline{10.1016 / j . e u r p o l y m j .2007 .09 .010}$

[21] Tartaglione G., Tabuani D., Camino G.: Thermal and morphological characterization of organically modified sepiolite. Microporous and Mesoporous Materials, 107, 161-168 (2008).

DOI: $\underline{10.1016 / \text { j.micromeso.2007.04.020 }}$

[22] Costache M. C., Jiang D. D., Wilkie C. A.: Thermal degradation of ethylene-vinyl acetate copolymer nanocomposites. Polymer, 46, 6947-6958 (2005). DOI: 10.1016/j.polymer.2005.05.084

[23] Schartel B., Hull T. R.: Development of fire-retarded materials - Interpretation of cone calorimeter data. Fire and Materials, 31, 327-354 (2007).

DOI: $10.1002 /$ fam. 949

[24] Bilotti E., Zhang R., Deng H., Quero F., Fischer H. R., Peijs T.: Sepiolite needle-like clay for PA6 nanocomposites: An alternative to layered silicates? Composites Science and Technology, 69, 2587-2595 (2009). DOI: 10.1016/j.compscitech.2009.07.016 